\title{
Anaerobic fungi in the digestive tract of mammalian herbivores and their potential for exploitation
}

\author{
B Y MICHAEL K. THEODOROU ${ }^{1}$, GEORGINA MENNIM ${ }^{1,2}$, \\ DAVID R. DAVIES ${ }^{1}$, WEI-YUN ZHU ${ }^{1}$, ANTHONY P. J. TRINCI ${ }^{2}$ \\ AND JAYNE L. BROOKMAN ${ }^{2}$ \\ ${ }^{1}$ Institute of Grassland and Environmental Research, Plas Gogerddan, Aberystwyth, \\ Dyfed $S Y 23$ 3EB \\ ${ }^{2}$ School of Biological Sciences, University of Manchester, Stopford Building, \\ Manchester M13 9PT
}

\section{ANAEROBIC FUNGI IN THE DIGESTIVE TRACT ECOSYSTEM}

Research into the microbiology of the rumen has been undertaken for many years with substantial contributions in bacteriology and protozoology being made during the $1940 \mathrm{~s}$, 1950s and 1960s. However, it was not until 1975 that Orpin (1975) identified the rumen anaerobic fungi. In fact, zoospores of anaerobic fungi were known since the early part of this century but were mistakenly identified as protozoan flagellates in rumen fluid (Liebetanz, 1910). According to Warner (1966), these flagellates were sequestered on the rumen epithelium, moving to the rumen fluid when the animal was feeding. This hypothesis was necessary to account for the large increase in protozoan flagellates in rumen fluid immediately after feeding. Orpin (1975) showed that the sequestered cells were not on the rumen wall but came from digesta particles, concluding that their abundance after feeding was due to their liberation from digesta-associated fungal zoosporangia. Two reasons can account for our failure to recognize the existence of anaerobic fungi until the mid-1970s. First, there was the persistent belief that all fungi required $\mathrm{O}_{2}$ to grow (Foster, 1949) and second, it was common practice amongst rumen microbiologists to work with strained rumen fluid, discarding the digesta solids and, thus, the digesta-associated fungal thalli (Bauchop, 1983).

\section{Life history and survival}

Anaerobic fungi have been assigned to the Order Neocallimasticales within the Class Chytridiomycetes (Munn, 1994). To date, five genera and fifteen species have been described (Theodorou et al. 1996b). Species are delimited mainly on details of zoospore ultrastructure, whereas genera are defined on the basis of monocentric or polycentric thallus, filamentous or bulbous rhizoids, and monoflagellated or polyflagellated zoospores.

The life-cycle of anaerobic fungi in the rumen consists of two stages where motile zoospores in rumen fluid alternate with fungal thalli which colonize and degrade digesta solids. A third stage, a survival stage, occurs in the lower gut and faeces (Davies et al. 1993; Nielsen et al. 1995). Life-cycles within the range of 24-32 h have been described in vitro, although under appropriate conditions in vivo zoosporogenesis can occur as little as $8 \mathrm{~h}$ after encystment (France et al. 1990; Theodorou et al. 1996b). Zoosporogenesis is influenced by chlorophyll breakdown products, and zoospores show a chemotactic 
(a)
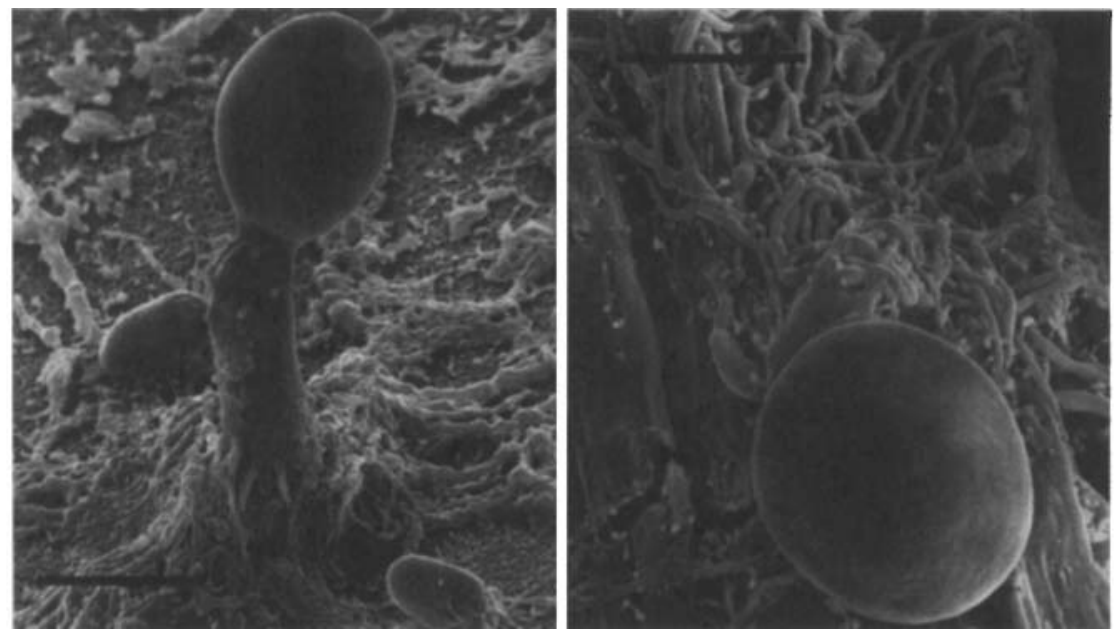

(b)

Fig. 1. Scanning electron micrograph of cryo-fixed Neocallimastix hurleyensis grown in liquid culture for $48 \mathrm{~h}$. (a) Oval zoosporangium and main rhizoid of a fungal thallus on a membrane filter., $10 \mu \mathrm{m}$. (After Lowe et al. 1987a.) (b) Fungal thallus with a spherical zoosporangium on hay. The branched, ramifying rhyomyoelium is seen colonizing the substrate.

, $25 \mu \mathrm{m}$. (After Theodorou et al. 1988.)

response to soluble sugars (Orpin \& Bountiff, 1978; Orpin \& Greenwood, 1986). These processes assist in the liberation of zoospores and help them to locate freshly-ingested plant biomass where they settle, encyst and germinate to produce a fungal thallus consisting of a rhizoidal system and one (monocentric) (Fig. 1 (a,b)) or more (polycentric) zoosporangia. In some genera the rhizoidal system is highly branched and tapering but in the Caecomyces it consists of one or more holdfasts or haustoria (Theodorou et al. 1996b). In monocentric genera, nuclei are present and multiply in the zoosporangium but are absent from the rhizoidal system (Lowe et al. 1987a). Thus, zoosporogenesis in monocentric fungi results in the production of an anucleated vegetative thallus without the capacity for further development. This is of consequence in the rumen where both zoospores and thalli are required for continued biomass production. Following zoospore release, the monocentric thallus rapidly autolyses (Lowe et al. 1987a,b) and, thus, is unlikely to provide nutrients for the host animal. Polycentric fungi do have nuclei in their rhizoids and, thus, they have an indeterminate life-cycle and are less dependent on the formation of zoospores for their continued survival (Theodorou et al. 1996b).

Anaerobic fungi, identical in appearance to the rumen fungi, have been isolated from ruminant faeces and the post-ruminal organs of the digestive tract (Davies et al. 1993). The fungi in faeces and in digesta from post-rumen organs remain viable when dried in air at ambient temperature. To account for these findings, the generally accepted life-cycle of the gut fungi was amended by inclusion of an additional survival cycle (Fig. 2). In this scheme, cycle $A$ is the vegetative cycle in the rumen, whereas cycle $B$ is the survival cycle activated when conditions for vegetative growth become less favourable. Resistant zoosporangia have recently been identified in dried faeces. These structures might be disseminated to herbage in nature and if subsequently eaten might account for transfer of anaerobic fungi between herbivores. 


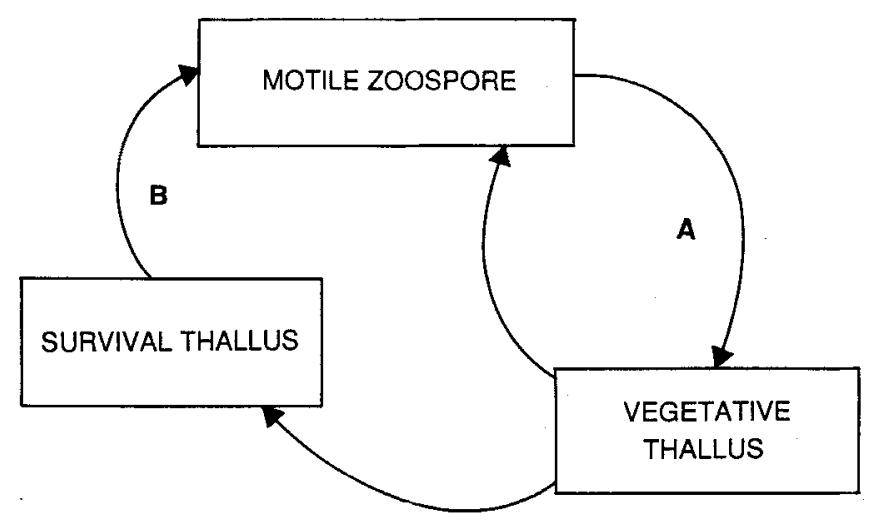

Fig. 2. Diagrammatic representation of the complete life-cycle of gut fungi. Cycle $A$ is the vegetative cycle purported to occur in the rumen. Cycle B is the survival cycle which occurs when conditions become unfavourable for vegetative growth. (After Davies et al. 1993.)

\section{Energy metabolism and fermentation}

Anaerobic fungi have no mitochondria and are unable to produce energy by either aerobic or anaerobic respiration (Yarlett et al. 1986; O'Fallon et al. 1991). Instead, they meet their energy needs by the fermentation of carbohydrates, a process in which the energy source acts as both the electron acceptor and the electron donor. Instead of mitochondria, anaerobic fungi have hydrogenosomes, organelles capable of coupling the metabolism of glucose to cellular energy production. Hydrogenosomes contain hydrogenase (EC 1.18.99.1) and produce $\mathrm{H}_{2}, \mathrm{CO}_{2}$ and acetate as metabolic waste products (Yarlett $e t$ al. 1986; Brul \& Stumm, 1994).

Anaerobic fungi use a wide range of polysaccharides and disaccharides for growth, although growth on monosaccharides is generally restricted to glucose, fructose and xylose (Lowe et al. 1987b; Phillips \& Gordon, 1988). These substrates are fermented via a mixedacid fermentation to give formate, acetate, lactate, ethanol, $\mathrm{CO}_{2}$ and $\mathrm{H}_{2}$ (Lowe et al. $1987 \mathrm{~b}$ ). Some of these products (formate, ethanol and lactate) are not typical of those found in the rumen. Their accumulation in axenic culture is thought to be due to the absence of methanogenic bacteria in culture and, thus, an absence of the microbial interaction associated with inter-species H transfer (Bauchop \& Mountfort, 1981). When cultured in the presence of methanogens, the fermentation profile of anaerobic fungi changes with the production of larger amounts of the more reduced products, formate and acetate. This shift in metabolism results in production of increased energy by the primary organism. Formate does not accumulate in the rumen in the presence of methanogens because they also use it as a substrate for growth.

\section{Plant cell-wall degradation}

The following account is presented as evidence to support the hypothesis that anaerobic fungi are primary colonizers of plant biomass in the digestive tract ecosystem. Anaerobic fungi can colonize and degrade a range of plant materials and agricultural by-products including temperate and tropical grasses, wheat straw, rice straw, maize stem, soyabean 
hulls and even highly recalcitrant materials such as palm press fibre and wood (Lowe et al. 1987c; Grenet \& Barry, 1988; Ho et al. 1991; Roger et al. 1992). Anaerobic fungi are often found to colonize and degrade plant material with a high phenolic content, such as lignified sclerenchyma and vascular tissues (Borneman et al. 1991, 1992). Plant particles recovered from the rumen of animals containing large fungal populations required less force to break them than particles recovered from animals with lower fungal populations (Akin et al. 1983). Appresorial-like structures, analogous to those found in fungal plant pathogens have been identified in anaerobic fungi (Ho et al. 1988). Appresoria enable pathogens to 'punch' holes through living plant cell walls, thus obtaining access to internal plant structures. Perhaps anaerobic fungi are able to gain entry to freshly-ingested herbage in this way to colonize plant structures as yet unavailable to rumen bacteria. France et al. (1990) have suggested that bacteria and fungi live in two different niches in the rumen, whereby bacteria degrade plant particles by surface erosion and fungi penetrate and degrade by invasive colonization. These two modes of attack are mutually beneficial in the rumen, permitting survival of two cellulolytic populations consuming the same substrates. In general, the previously described observations support the view that anaerobic fungi are important in the digestive tract ecosystem, particularly where animals feed on highly fibrous diets. To date, most research with gut fungi has been conducted using artificial substrates such as filter paper cellulose, dried plant particles, or cut plant fragments (Lowe et al. 1987b; Theodorou et al. 1989; Akin et al. 1990). Little attention has been given to the colonization of intact, living plant biomass in ruminants. In grazing ruminants, the majority of the plant cells are living on entering the rumen and presumably they are colonized by microbial populations during cell death. Perhaps this is when the gut fungi play their most significant role in the rumen, during these initial stages of microbial colonization.

\section{ENZYMOLOGY}

Plant biomass consists predominantly of cellulose (280-500 g/ $\mathrm{kg}$ ), hemicellulose (200-300 $\mathrm{g} / \mathrm{kg}$ ) and lignin (180-300 g/kg; Ljungdahl \& Eriksson, 1984), with pectin contributing up to $100 \mathrm{~g} / \mathrm{kg}$ dry weight of some forages (Van Soest, 1982). To facilitate primary colonization of plant-cell-wall material, gut fungi produce a range of cell-wall-degrading enzymes. These enzymes are present on the fungal surface, localized on rhizoids or rhizomycellia, with a larger proportion being secreted into the extracellular environment (Lowe et al. $1987 b, c$ ). The enzymes found to date, their characteristics and the cell wall structures they degrade are now described.

\section{Cellulose, cellulases and glucosidases}

Cellulose is a linear polymer of several thousand glucose residues linked by $\beta-(1-4)$ glucosidic bonds with the dimer, cellobiose (Fig. 3), acting as the repeating unit. Intermolecular $\mathrm{H}$ bonds between the adjacent cellulose chains cause them to adhere tightly to each other in overlapping parallel arrays forming ordered rigid cellulose fibrils which are partly crystalline in character. Cellulose chains also exist which can cross from one fibril to another, resulting in non-crystalline, amorphous regions. These amorphous regions are thought to be less resistant to microbial degradation than the crystalline regions (Ljungdahl \& Eriksson, 1984). 
(A)

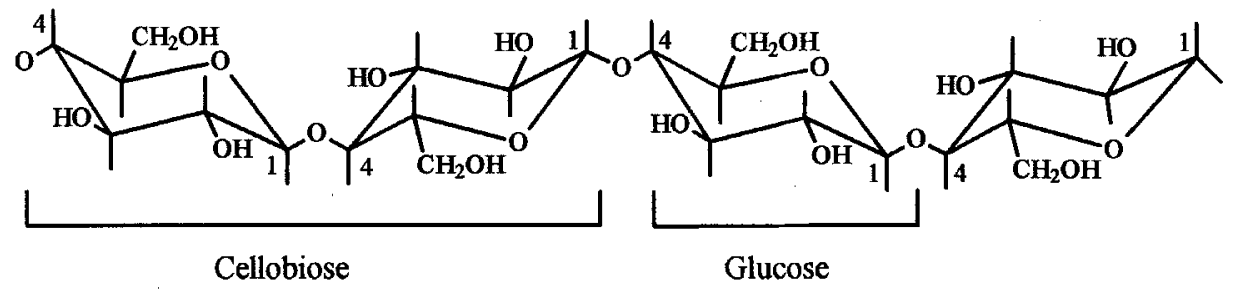

(B)

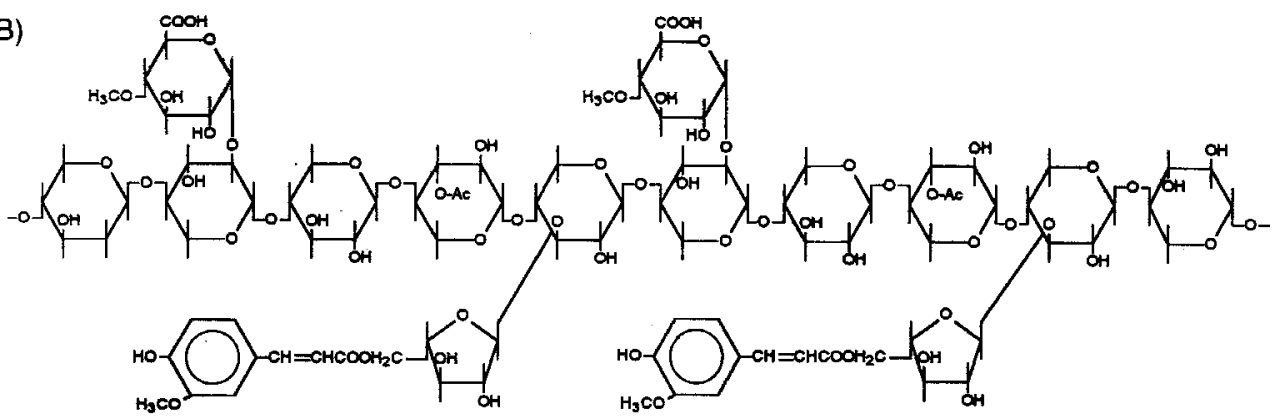

Fig. 3. (A) $\beta$-Glucosidic bonds between glucose units in the cellulose polymer. (After Béguin \& Aubert,

1994.) (B) Typical cereal arabino-4-0-methylglucuronoxylan. (After Coughlan \& Hazlewood, 1993.)

Cellulose degradation by gut fungal enzymes has been investigated and the mechanism employed appears to be more closely related to that of the anaerobic rumen bacteria than the cellulolytic aerobic fungi such as Trichoderma reesei. The anaerobic rumen bacteria and apparently the gut fungi have an identifiable extracellular macromolecular complex of cellobiohydrolases called a cellulosome, whereas the cellulase components of $T$. reesei do not aggregate (Wilson \& Wood, 1992). The cellulosomes in gut fungi contain the following enzyme activities: exo-1,4- $\beta$-D-glucanases (cellobiohydrolases), endo-1,4- $\beta$-D-glucanases, and $\beta$-glucosidase (EC 3.2.1.21; Wood, 1991), which are required to act in synergy to convert crystalline cellulose to glucose (Wood \& Garcia-Campayo, 1990; Perrson et al. 1991; Wood, 1991). It is thought that the initial attack on the cellulose molecule is by the endo-glucanase, which cuts the linear cellulose chains internally. Exo-glucanase can then act at these nick sites, releasing cellobiose, which is in turn hydrolysed by $\beta$-glucosidase (cellobiase) to glucose monomers (Bisaria \& Ghose, 1981).

Gut fungal cellulases and related hemicellulases have been shown to be modular in structure (Gilbert et al. 1992; Zhou et al. 1994). They contain one or more catalytic domains linked by regions rich in hydroxy amino acids to a highly-conserved non-catalytic cellulose-binding domain and/or to a putative protein docking domain. The docking domain has recently been described by Fanutti et al. (1995) and may be involved in the formation of cellulase (EC 3.2.1.4) and hemicellulase complexes.

These enzymes are interesting in that many have a significant degree of sequence homology with bacterial enzymes. One of the cloned endoglucanases, $c e l b$, has no introns and has sequence and structural homology to bacterial family A endoglucanases (Zhou et al. 1994). This evidence indicates that evolution of the gut fungal cellulase system may have involved extensive transfer of genes between anaerobic bacteria and fungi in the rumen (Zhou et al. 1994). Another interesting type of cellulase (celD) is found as a single 
copy coding for a modular multi-functional polysaccharide hydrolase with three catalytic domains, each individual domain possessing activity against a variety of cellulose and hemicellulose substrates (Xue et al. 1992).

A great deal of interest has been generated by the observed activities of the gut fungal hydrolases. Wood et al. (1986) reported that a unit of gut fungal endoglucanase (from cellfree preparations of fungus-methanogenic bacterium co-culture) was several times more active than that from Trichoderma reesei $\mathrm{C}-30$, which is considered to be one of the most active cellulases reported to date. Other enzymes have also been shown to have remarkably high activities. These high activities could be the result of the highly competitive environment within the rumen, or they may be a result of the high metabolic cost of producing proteins in an anaerobic environment, causing a pressure to make the most effective use of available resources.

\section{Hemicellulose and hemicellulases}

Hemicelluloses differ from cellulose in that they are of heterogeneous composition, consisting of various sugar units, and have shorter, more branched chains (Fig. 3). They are composed of various hexoses, pentoses and uronic acids, with most hemicelluloses containing two to six different sugar residues. Classification of hemicellulose is based on the sugar residues present within the backbone, for example xylans are composed of D-xylose, mannans of D-mannose, arabinans of L-arabinose and galactans of D-galactose units.

Xylans are highly-branched heteropolymers with a backbone of $\beta$-(1-4)-linked D-xylopyranosyl residues and attached acetyl, arabinosyl, and glucosyluronic acid residues. Phenolic substituents which are covalently bound via arabinosyl residues are also present, particularly in xylans from cereals. Xylan degradation is not fully understood but is thought to require the combined action of endo-(1-4)- $\beta$-D-xylanase (EC 3.2.1.8), $\beta$-xylosidase $(E C$ 3.2.1.37), and enzymes responsible for cleaving the side groups, e.g. esterases. Anaerobic fungi have been shown to produce all the enzymes necessary to degrade xylan (Orpin \& Letcher, 1979; Pearce \& Bauchop, 1985; Lowe et al. 1987c; Teunissen et al. 1991).

There have been two xylanase activities cloned from anaerobic gut fungi. Xylanase A (EC 3.2.1.32; XYLA) has a modular structure, consisting of two catalytic domains joined by a threonine- and proline-rich linker region. Sequence comparison has revealed significant homology between the catalytic domains of XYLA and the bacterial xylanases belonging to the xylanase family $G$ (Gilbert et al. 1992). Xylanase B is composed of a single catalytic domain, which exhibits homology to the family of F xylanases (Black et al. 1994). This dual expression of bacterial and fungal types of activities mirrors the coexistence of bacteria- and fungal-like cellulase genes within the gut fungi.

Along with xylan, mannan is one of the two major hemicellulose components of both hardwoods and softwoods (Coughlan \& Hazlewood, 1993). Fanutti et al. (1995) have recently cloned a gut fungal mannanase (EC 3.2.1.25) gene from a Piromyces sp. and revealed an amino acid sequence homology with bacterial mannases belonging to the glycosyl hydrolase family 26 . The gene sequence also contained a reiterated sequence thought to be a putative protein docking domain that is homologous to the reiterated sequence present in XYLA described by Gilbert et al. (1992). Once more this indicates substantial horizontal gene transfer between bacteria and fungi in the rumen. 


\section{Pectin-degrading enzymes}

Pectins are heterogeneously-branched polysaccharides that contain many negatively charged galacturonic acid residues. Pectins are considered to be partially-methyl-esterified rhamnogalacturans in which rhamnose units are inserted, and in which sugars like galactose and arabinose occur in short side chains. Some neutral sugars such as arabinose, galactans and arabinogalactans are often associated with pectin (Theander, 1989).

Although pectin is an important constituent of plant biomass, there is some disagreement about whether anaerobic fungi can utilize pectin as the only $\mathrm{C}$ source. Several studies have demonstrated the loss of pectin from fungus-degraded forage and the presence of low levels of pectin-degrading enzymes in culture filtrates (Orpin, 1983-4; Williams \& Orpin, 1987). It is possible that pectin, lignin and hemicellulose linkages may limit access to some of the plant cell wall polymers, and that the ability to degrade pectin may allow fungal enzymes access to these otherwise inaccessible carbohydrates.

\section{Esterases}

Phenolic acids ( $p$-coumaric and ferulic acid) in plant cell walls form cross linkages between xylan, hemicellulose and lignin, with $p$-coumaric and feruloyl moieties mainly associated with lignin and hemicellulose respectively (Atushi et al. 1984; Scalbert et al. 1985; Chesson, 1988). Up to 50\% of the arabinosyl side residues of the xylan and hemicellulose side chains may be linked or esterified in this way (Chesson \& Fosberg, 1988). These complexes may protect the xylan and hemicellulose from attack by micro-organisms and their enzymes. The sugar residues of hemicellulose may be substituted by acetyl groups, particularly in hardwoods and grass cell walls. It is thought that the acetyl groups help to stabilize the structure of hemicellulose, preventing formation of a more-highly-ordered crystalline structure and microbial breakdown of the polysaccharide (Mitchell et al. 1990). Anaerobic fungi have been shown to produce acetyl xylan esterases, feruloyl esterase and $p$-coumaroyl esterase. These enzymes may have a role in cleaving $p$-coumaroyl and feruloyl residues from the lignin-hemicellulose complexes, loosening cell wall structures, thereby allowing access to previously protected polysaccharides. Gut fungal esterases, therefore, may confer anaerobic fungi with unique advantages, enabling them to preferentially colonize and degrade lignified plant biomass (Borneman \& Akin, 1990; Borneman et al. 1991, 1992). Esterases have been purified and characterized (Borneman et al. 1991, 1992) but to date no esterases have been cloned.

\section{Lignin degradation}

Lignin provides rigidity and mechanical support to plants and is thought to be covalently linked to cell-wall-matrix polysaccharides via ester bonds with uronic acid residues as well as via phenolic acids. The phenylpropane units are composed of $p$-coumaryl, coniferyl and sinapyl alcohols joined by a variety of linkages, of which the three major ones are the aryl-aryl, phenyl-coumaryl and bi-phenyl bonds. The encrusting and linking of cellulose and non-cellulosic polysaccharides by lignin gives cell walls mechanical strength and hydrophobicity, as well as decreasing accessibility to micro-organisms and degrading enzymes (Akin \& Chesson, 1989). Culture filtrates of anaerobic fungi have been shown to solubilize lignin from milled barley cell walls (Zimmerman \& Broda, 1989) and 
supernatant solutions from an artificial rumen reactor have been shown to contain ligninderived compounds, presumably released by the rumen micro-organisms (Kivaisi et al. 1990). However, it is unlikely that anaerobic fungi produce the enzymes necessary to degrade the lignin molecule itself because ring cleavage requires molecular oxygen. It is more likely that anaerobic fungi cut the bonds which join the lignin molecules to other molecules in the cell wall (e.g. using esterases) releasing the lignin and allowing enzymes access to the other polysaccharide molecules.

\section{Proteolytic enzymes}

Glycoproteins can account for $10 \%$ of the mass of the primary cell wall, and so possession of active proteases would provide gut fungi with a useful source of nutrients. The activity of gut fungal protease(s) is comparable with the most active proteolytic rumen bacteria but low in comparison with some aerobic fungi (Wallace \& Joblin, 1985). Proteases in anaercbic fungi may provide amino acids for growth, modify the activity of other extracellular enzymes, or assist in the penetration of plant material. It is unclear, however, if gut fungal protease makes a significant contribution to the degradation of dietary proteins in the rumen. Indeed, it has been proposed that the contribution made by rumen micro-organisms to this process is minimal and that the most significant contribution is made by proteases from within the plants themselves (Theodorou et al. 1996a). Work is currently underway in our laboratories to test this hypothesis.

\section{FUTURE DIRECTIONS}

There are approximately $7.2 \times 10^{11}$ tonnes cellulosic material on planet Earth, with cellulose synthesized at a rate of about $70 \mathrm{~kg}$ per person per $\mathrm{d}$. Much of this plant biomass is considered an expensive waste, rather than a useful resource, and is either burnt or left to rot. The structural polysaccharide contained within this resource is equivalent to a vast reserve of simple sugars which, if liberated, could be used in many biotechnological processes. In this regard, the anaerobic fungi are of great potential in agro-industrial processes. Some areas are outlined here, where we suggest that anaerobic fungi may be of increasing importance within the next decade.

\section{Improvement in rumen function}

Anaerobic fungi have been found in both ruminant and single-stomached herbivores, from the largest (elephant; Elephas maximus) to the smallest (blue duiker; Cephalus monticola) mammals (Milne et al. 1989; Dehority \& Varga, 1991). World-wide, anaerobic fungi have been isolated from at least nineteen different countries from numerous fore-gut- (thirty-one species) and hind-gut-fermenting (nine species) herbivores (Theodorou et al. 1996b). These reports suggest that anaerobic fungi are ubiquitous among mammalian herbivores. We have characterized numerous gut fungal isolates for their ability to degrade wheat straw, an indicator of their enzymic activity. In general, isolates taken from animals fed on highlyfibrous diets were most able to degrade wheat straw in vitro. It has been shown that host animals fed on a soft leafy diet have proportionately fewer fungi and more bacteria in their guts than animals fed on a tough fibrous diet. This may be due to the increased rate of 
passage of soft fodder, favouring the more-quickly-reproducing rumen bacteria. Perhaps it is possible to inoculate the highly effective straw-degrading isolates into domestic ruminants not normally harbouring them, thereby enhancing the animals' ability to degrade poorer-quality forages. We are currently developing a membrane-based DNA assay, using ribosomal internal transcribed sequences (ITS1) as specific probes for the identification of individual fungal isolates. We aim to assay the maintenance of an introduced fungal isolate within the rumen by direct sampling and DNA assay. Further work will be required to determine whether the 'high enzyme' isolates produce more enzymes of inherently higher activity. An understanding of these differences in enzyme production and activity would perhaps make it possible to use direct mutagenesis and selection to produce more efficient degraders.

\section{Isolated and cloned enzymes}

The cell-wall-degrading enzymes of anaerobic fungi show potential for use in the pretreatment of animal feed. Single-stomached animals such as pigs and chickens do not maintain these fungi in their gut, and have a microbial population and gut function which restricts the range of feed components they can digest. Gut fungal enzymes could be used to increase the nutritional value of feeds given to single-stomached animals, or domestic ruminants, by pre-digestion or inclusion of the required enzymes in the feed mix. The use of enzyme supplements in feed would require either purified or semi-pure enzymes. These could be purified directly from the gut fungal cultures, or by heterologous expression of a cloned gene product in a foreign host, such as Aspergillus or Bacillus, for which industrialscale culture processes already exist. The latter approach would be more appropriate for commercial-scale applications as the gut fungi have low yields and have not yet been cultured at an industrial level. Enzymes from aerobic sources are already being used to enhance the nutritive value of feeds for single-stomached animals. For example, the pentosans in the endosperm of wheat and rye in chicken feed are responsible for poor nutrient uptake in the chicken gut (Choct \& Annison, 1992), but they can be removed by treating the grain with crude xylanase preparations (Pettersson \& Åman, 1989). The addition of glucanases and pentosanases (endoxylanases) to poultry diets containing barley, wheat, rye and oats has been shown to significantly enhance growth (Bedford \& Classen, 1992). Phytase ( $E C$ 3.1.3.8) is another enzyme of use in the feed industry. The addition of microbial phytase to poultry feed increases $\mathrm{P}$ availability by more than $60 \%$ and reduces $\mathrm{P}$ in the droppings by $30 \%$ (Christensen, 1995).

Alternatively it may be possible to manipulate rumen function directly by introducing novel gut fungal enzymes cloned and expressed in a host, such as Bacteroides fibrisolvens, a ubiquitous resident of the rumen. These methods would rely on the ability of geneticallymodified micro-organisms to compete with the native flora and be retained within the rumen ecosystem. This approach requires an intricate understanding of rumen microbial ecology, perhaps far in excess of our current knowledge and is obviously less simple to initiate than is the direct treatment of feed constituents with hydrolytic enzymes.

\section{Transgenic plants and animals}

Another very exciting field, which is quite different from those listed previously is the 
direct expression of plant-polymer-degrading enzymes in plants or even in the gut epithelial cells of ruminant animals. Expression of the enzymes in this way could be more efficacious and cost-effective than adding enzyme to feed, because the plant is fed directly to the animal with no need for down-stream processing of the enzyme(s). To be effective, expression of these enzymes would have to be regulated and controlled. In plants, for example, the proteins could be placed under the control of a senescence promoter which responds to seasonal changes (day length) or mechanical damage, i.e. during ensilage or possibly chewing. The direct expression of microbial proteins in an animal would require plant enzymes to be expressed in the gut tissue, be secreted into the gut lumen and be active under the conditions that prevail in the gut. Obviously, these transgenic approaches, including manipulation of the rumen microbial populations by molecular means, raise ethical questions not encountered when considering exploitation by pretreatment of animal feed.

\section{Non-animal-feed uses for the enzymes}

There are a large number of non-feed uses for fibrolytic enzymes. These range from the production of saccharification syrups for food and industrial fermentation, to single-cellprotein and antibiotic production, to anaerobic waste disposal to fuel methane and compost production. Waste management of agricultural, forestry and municipal wastes by the bioconversion of lignocellulosic residues could be a major user of gut fungal enzymes. The selective removal of hemicelluloses is an important part of many food, pulp and paper processes. For example, xylanase in the pre-bleaching of kraft pulp and pectinases in the pectinolytic de-barking of tree trunks and clarification of fruit juices (Wong \& Saddler, 1993). Mannase (EC 3.2.1.25) is used to reduce the viscosity of coffee, making freezedrying easier and cheaper. In the textile industry, purified cellulose is used to make viscose, rayons, cellulose esters and cellulose ethers. Xylan impurities cause colour haze and thermal instability in these products and this can be partially removed using xylanases (Wong \& Saddler, 1993). Cellulases are also used in the textile industry for cotton texturing and in the production of stone-washed jeans.

\section{CONCLUSIONS}

Gut anaerobic fungi have evolved over millions of years as fibrolytic saprophytes in the digestive tract of mammalian herbivores. They account for up to $8 \%$ of the microbial biomass in the rumen and are believed to participate as primary colonizers of plant cell walls (Bauchop, 1979a,b; Kemp et al. 1984). Although the extent of their contribution to plant-cell-wall degradation remains unclear, their activity is attributable to the production of a wide range of cell-bound and cell-free enzymes, including cellulases, hemicellulases, xylosidases, glucosidases, esterases, pectinases and proteases (Theodorou et al. 1996b). These enzymes enable gut fungi to degrade even the most recalcitrant of plant structural polysaccharides. Anaerobic fungi have certain unique characteristics which make them potentially exploitable in industry and agriculture. In the present review we have described the anaerobic fungi in relation to their role in the digestive tract ecosystem and provided an account of their enzyme activities and considered their potential for exploitation in industry and agriculture. 
We are grateful to Diane Davies for assistance during the preparation of this manuscript. Part of the work reported was supported by a LINK Crops for Industrial Use Scheme and financial assistance from Genencore International.

\section{REFERENCES}

Akin, D. E., Borneman, W. S. \& Lyon, C. E. (1990). Degradation of leaf blades and stems by monocentric and polycentric isolates of ruminal fungi. Animal Feed Science and Technology 31, 205-221.

Akin, D. E. \& Chesson, A. (1989). Lignification as a major factor limiting forage feeding value especially in warm conditions. Proceedings of the International Grassland Congress 16, 1753-1760.

Akin, D. E., Gordon, G. L. R. \& Hogan, J. P. (1983). Rumen bacterial and fungal degradation of Digitaria pentzii grown with or without sulfur. Applied Environmental Microbiology 46, 738-748.

Atushi, K., Azuma, J.-I. \& Koshijima, T. (1984). Lignin-carbohydrate complexes and phenolic acids in bagasse. Holzforschung 38, 141-149.

Bauchop, T. (1979a). Rumen anaerobic fungi of cattle and sheep. Applied Environmental Microbiology 38, $148-158$.

Bauchop, T. (1979b). The rumen anaerobic fungi: colonizers of plant fibre. Annales de Recherches Veterinaires 10, 246-248.

Bauchop, T. (1983). The gut anaerobic fungi: colonisers of dietary fibre. In Fibre in Human and Animal Nutrition, pp. 143-148 [G. Wallace and L. Bell, editors]. Wellington: Royal Society of New Zealand.

Bauchop, T. \& Mountfort, D. O. (1981). Cellulose fermentation by a rumen anaerobic fungus in both the absence and presence of rumen methanogens. Applied Environmental Microbiology 42, 1103-1110.

Bedford, M. R. \& Classen, H. L. (1992). Reduction of intestinal viscosity through manipulation of dietary rye and pentosanase concentration is effected through changes in the carbohydrate composition of the intestinal aqueous phase and results in improved growth rate and food conversion efficiency of broiler chicks. Journal of Nutrition 122, 560-569.

Béguin, P. \& Aubert, J.-P. (1994). The biological degradation of cellulose. FEMS Microbiology Reviews 13, $25-58$.

Bisaria, V. S. \& Ghose, T. K. (1981). Biodegradation of cellulosic materials: substrates, microorganisms, enzymes and products. Enzymes Microbiology and Technology 3, 90-104.

Black, G. W., Hazlewood, G. P., Xue, G.-P., Orpin, C. G. \& Gilbert, H. J. (1994). Xylanase B from Neocallimastix patriciarum contains a non-catalytic 455-residue linker sequence comprised of an octapeptide. Journal of Biochemistry 299, 560-569.

Borneman, W. S. \& Akin, D. E. (1990). Lignocellulose degradation by rumen fungi and bacteria: Ultrastructure and cell wall degrading enzymes. In Microbial and Plant Opportunities to Improve Lignocellulose Utilization by Ruminants, pp. 325-340 [D. E. Akin, L. G. Ljungdahl, J. R. Wilson and P. J. Harris, editors]. New York: Elsevier Publishing Co. Inc.

Borneman, W. S., Ljungdahl, L. G., Hartley, R. D. \& Akin, D. E. (1991). Isolation and characterization of p-coumaroyl esterase from the anaerobic Neocallimastix strain MC-2. Applied Environmental Microbiology 57, 2337-2344.

Borneman, W. S., Ljungdahl, L. G., Hartley, R. D. \& Akin, D. E. (1992). Purification and partial characterisation of 2 feruloyl esterases from the anaerobic fungus Neocallimastix strain MC-2. Applied Environmental Microbiology 58, 3762-3766.

Brul, S. \& Stumm, C. K. (1994). Symbionts and organelles in anaerobic protozoa and fungi. Tree 9, 319-324.

Chesson, A. (1988). Lignin-polysaccharide complexes of the plant cell wall and their effect on microbial degradation in the rumen. Animal Feed Science and Technology 21, 219-228.

Chesson, A. \& Forsberg, C. W. (1988). Polysaccharide degradation by rumen microorganisms. In The Rumen Microbial Ecosystem, pp. 251-284 [P. H. Hobson, editor]. New York: Elsevier Applied Sciences.

Choct, M. \& Annison, G. (1992). The inhibition of nutrient digestion by wheat pentosans. British Journal of Nutrition 67, 123-132.

Christensen, L. (1995). Phytase Novo cuts phosphorus in manure by 30\%. BioTimes, vol. 3, pp. 8-9. Bagsvaerd, Denmark: Novo Nordisk. 
Coughlan, M. P. \& Hazlewood, G. P. (1993). $\beta$-1,4-D-Xylan-degrading enzyme systems: biochemistry, molecular biology and applications. Biotechnology and Applied Biochemistry 17, 259-289.

Davies, D. R., Theodorou, M. K., Lawrence, M. I. \& Trinci, A. P. J. (1993). Distribution of anaerobic fungi in the digestive tract of cattle and their survival in faeces. Journal of General Microbiology 139, 1395-1400.

Dehority, B. A. \& Varga, G. A. (1991). Bacterial and fungal numbers in ruminal and caecal contents of the Blue Duiker (Cephalus monticola). Applied Environmental Microbiology 57, 469-472.

Fanutti, C., Ponyi, T., Black, G. W., Hazlewood, G. P. \& Gilbert, H. J. (1995). The conserved non-catalytic 40residue sequence in cellulases and hemicellulases from anaerobic fungi functions as a protein docking domain. Journal of Biological Chemistry 270, 29314-29322.

Foster, J. W. (1949). Chemical Activities of the Fungi. New York: Academic Press.

France, J., Theodorou, M. K. \& Davies, D. (1990). The use of zoospore concentrations and life cycle parameters in determining the population of anaerobic fungi in the rumen ecosystem. Journal of Theoretical Biology 147, $413-422$.

Gilbert, H. J., Hazlewood, G. P., Laurie, J. I., Orpin, C. G. \& Xue, G. P. (1992). Homologous catalytic domains in a rumen fungal xylanase: evidence for gene duplication and prokaryotic origin. Molecular Microbiology 6, 2065-2072.

Grenet, E. \& Barry, P. (1988). Colonization of thick-walled plant tissues by anaerobic fungi. Animal Feed Science and Technology 19, 25-31.

Ho, Y. W., Abdullah, N. \& Jalaludin, S. (1988). Penetrating structures of anaerobic rumen fungi in cattle and swamp buffalo. Journal of General Microbiology 134, 177-181.

Ho, Y. W., Abdullah, N. \& Jalaludin, S. (1991). Fungal colonization of rice straw and palm press fibre in the rumen of cattle and buffalo, Animal Feed Science and Technology 34, 311-321.

Kemp, P., Lander, D. J. \& Orpin, C. G. (1984). The lipids of the rumen fungus Piromonas communis. Journal of General Microbiology 130, 27-37.

Kivaisi, A. K., Op den Camp, H. J. M., Lubberding, H. J., Boon, J. J. \& Vogels, G. D. (1990). Generation of soluble lignin-derived compounds during degradation of barley straw in an artificial rumen reactor. Applied Microbiology and Biotechnology 33, 93-98.

Liebetanz, E. (1910). Die parasitischen Protozoen des Wiederkauermayens (The parasitic protozoa of ruminant stomachs). Archives Protistenkunde 19, 19-80.

Ljungdahl, L. G. \& Erickson, K. E. (1984). Ecology of microbial cellulose degradation. Advances in Microbial Ecology 8, 237-299.

Lowe, S. E., Griffith, G. G., Milne, A., Theodorou, M. K. \& Trinci, A. P. J. (1987a). Life cycle and growth kinetics of an anaerobic rumen fungus. Journal of General Microbiology 133, 1815-1827.

Lowe, S. E., Theodorou, M. K. \& Trinci, A. P. J. (1987b). Growth and fermentation of an anaerobic rumen fungus on various carbon sources and effect of temperature on development. Applied Environmental Microbiology 53, 1210-1215.

Lowe, S. E., Theodorou, M. K. \& Trinci, A. P. J. (1987c). Cellulases and xylanase of an anaerobic rumen fungus grown on wheat straw, wheat straw holocellulose, cellulose and xylan. Applied Environmental Biology 53, $1216-1223$.

Milne, A., Theodorou, M. K., Jordan, M. G. C., King-Spooner, C. \& Trinci, A. P. J. (1989). Survival of anaerobic fungi in faeces, in saliva, and in pure culture. Experimental Mycology 13, 27-37.

Mitchell, D. J., Grohmann, K. \& Himmel, M. E. (1990). Effect of the degree of acetylated xylans. Journal of Wood Chemistry and Technology 10, 111-121.

Munn, E. A. (1994). The ultrastructure of anaerobic fungi. In The Anaerobic Fungi, pp. 47-105 [C. G. Orpin and D. O. Mountfort, editors]. New York: Marcel Dekker.

Nielsen, B. B., Zhu, W.-Y., Trinci, A. P. J. \& Theodorou, M. K. (1995). Demonstration of zoosporangia of anaerobic fungi on plant residues recovered from faeces of cattle. Mycological Research 99, 471-474.

O'Fallon, J. V., Wright, R. W. \& Calza, R. E. (1991). Glucose metabolic pathways in the anaerobic rumen fungus Neocallimastix frontalis EB 188. Biochemical Journal 274, 595-599.

Orpin, C. G. (1975). Studies on the rumen flagellate Neocallimastix frontalis. Journal of General Microbiology 91, 249-262.

Orpin, C. G. (1983-4). The role of ciliate protozoa and fungi in the rumen digestion of plant cell walls. Animal Feed Science and Technology 10, 121-143. 
Orpin, C. G. \& Bountiff, L. (1978). Zoospore chemotaxis in the rumen phycomycete Neocallimastix frontalis. Journal of General Microbiology 104, 113-122.

Orpin, C. G. \& Greenwood, Y. (1986). The role of haems and related compounds in the nutrition and zoosporogenesis of the rumen chytridiomycete Neocallimastix frontalis H8. Journal of General Microbiology $132,2179-2185$.

Orpin, C. G. \& Letcher, A. J. (1979). Utilization of cellulose, starch, xylan and other hemicelluloses for growth by the rumen phycomycete Neocallimastix frontalis. Current Microbiology 3, 121-124.

Pearce, P. D. \& Bauchop, T. (1985). Glycosidases of the rumen anaerobic fungus Neocallimastix frontalis grown on cellulosic substrates. Applied Environmental Microbiology 49, 1265-1269.

Persson, I., Tjerneld, F. \& Hahn-Hägerdal, B. (1991). Fungal cellulolytic enzyme production: a review. Processes in Biochemistry 26, 65-74.

Pettersson, D. \& Åman, P. (1989). Enzyme supplementation of a poultry diet containing rye and wheat. British Journal of Nutrition 62, 139-149.

Phillips, M. W. \& Gordon, G. L. R. (1988). Sugar and polysaccharide fermentation by anaerobic fungi from Australia, Britain and New Zealand. Biosystems 21, 377-383.

Roger, V., Grenet, E., Jamot, J., Bernalier, A., Fonty, G. \& Gouet, P. (1992). Degradation of maize stem by two rumen fungal species, Piromyces communis and Caecomyces communis, in pure cultures or in association with cellulolytic bacteria. Reproduction Nutrition Développement 32, 321-329.

Scalbert, A., Monties, B., Lallemand, J. Y., Guittet, E. \& Rolando, C. (1985). Ether linkage between phenolic acids and lignin fractions from wheat straw. Phytochemistry 24, 1359-1362.

Teunissen, M. J., Op den Camp, H. J. M., Orpin, C. G., Huis, J. H. J. \& Vogels, G. D. (1991). Comparison of growth characteristics of anaerobic fungi isolated from ruminant and non-ruminant herbivores during cultivation in a novel defined medium. Journal of General Microbiology 137, 1401-1408.

Theander, O. (1989). Plant cell walls - Their chemical properties and rumen degradation. In The Roles of Protozoa and Fungi in Ruminant Degradation, OECD/UNE International Seminar, pp. 1-12 [J. V. Nolan, R. A. Leng and D. I. Demeyer, editors]. Armidale, NSW: Penambul Books.

Theodorou, M. K., Longland, A. C., Dhanoa, M. S., Lowe, S. E. \& Trinci, A. P. J. (1989). Growth of Neocallimastix sp strain R1: on Italian ryegrass hay: removal of neutral sugars from plant cell walls. Applied Environmental Microbiology 55, 1363-1367.

Theodorou, M. K., Lowe, S. E. \& Trinci, A. P. J. (1988). The fermentative characteristics of anaerobic fungi. Biosystems 21, 371-376.

Theodorou, M. K., Merry, R. J. \& Thomas, H. (1996a). Is proteolysis in the rumen of grazing animals mediated by plant enzymes? (letter). British Journal of Nutrition 75, 507.

Theodorou, M. K., Zhu, W.-Y., Rickers, A., Nielsen, B. B., Gull, K. \& Trinci, A. P. J. (1996b). In The Mycota, vol. 6, Human and Animal Relationships. Berlin and Heidelberg: Springer-Verlag.

Van Soest, P. J. (1982). Nutritional Ecology of the Ruminant. Corvallis, OR: Durham \& Downey. Inc.

Wallace, R. J. \& Joblin, N. J. (1985). Proteolytic activity of a rumen anaerobic fungus. FEMS Microbiology Letters 29, 9-25.

Warner, A. C. S. (1966). Diurnal changes in the concentration of microorganisms in the rumen of sheep fed limited diets once daily. Journal of General Microbiology 45, 213-235.

Williams, A. G. \& Orpin, C. G. (1987). Polysaccharide-degrading enzymes formed by three species of anaerobic rumen fungi grown on a range of carbohydrate substrates. Canadian Journal of Microbiology 33, 418-426.

Wilson, C. A. \& Wood, T. M. (1992). The anaerobic fungus Neocallimastix frontalis: isolation and properties of a cellulosome-type enzyme fraction with the capacity to solubilize hydrogen-bond-ordered cellulose. Applied Microbiology and Biotechnology 37, 125-129.

Wong, K. K. Y. \& Saddler, J. N. (1993). Applications of hemicellulases in the food, feed and pulp industries. In Hemicellulose and Hemicellulases, Portland Press Research Monograph, pp. 127-143 [M. P. Coughlan and G. P. Hazlewood, editors]. London: Portland Press.

Wood, T. M. (1991). Fungal cellulases. In Biosynthesis and Biodegradation of Cellulose, pp. 499-533 [C. H. Haigler and P. J. Weimer, editors]. New York: Marcel Dekker Inc.

Wood, T, M. \& Garcia-Campayo, V. (1990). Enzymology of cellulose degradation. Biodegradation 1, 147-161.

Wood, T. M., Wilson, C. A., McCrae, S. I. \& Joblin, K. N. (1986). A highly active extracellular cellulase from the anaerobic rumen fungus Neocallimastix frontalis. FEMS Microbiology Letters 34, 37-40. 
Xue, G. P., Gobius, K. S. \& Orpin, C. G. (1992). A novel polysaccharide hydrolase cDNA (cedD) from Neocallimastix patriciarum encoding three multi-functional catalytic domains with high endoglucanase, cellobiohydrolase and xylanase activities. Journal of General Microbiology 138, 2397-2403.

Yarlett, N., Orpin, C. G., Munn, E. A., Yarlett, N. C. \& Greenwood, C. A. (1986). Hydrogenosomes in the rumen fungus Neocallimastix patriciarum. Journal of Biochemistry 236, 729-739.

Zhou, L., Xue, G.-P., Orpin, C. G., Black, G. W., Gilbert, H. J. \& Hazlewood, G. P. (1994). Intronless celB from the anaerobic fungus Neocallimastix patriciarum encodes a modular family A endoglucanase. Journal of Biochemistry 297, 359-364.

Zimmerman, W. \& Broda, P. (1989). Utilization of lignocellulose from barley straw by actinomycetes. Applied Microbiology and Biotechnology 30, 103-110. 